\title{
Coir Fibers as Valuable Raw Material for Biofuel Pellet Production
}

\author{
Wolfgang Stelte ${ }^{1}\left(\right.$ D Søren T. Barsberg ${ }^{2} \cdot$ Craig Clemons $^{3} \cdot$ João Paulo Saraiva Morais ${ }^{4} \cdot$ Morsyleide de Freitas Rosa $^{5}$. \\ Anand R. Sanadi ${ }^{2}$
}

Received: 31 January 2018 / Accepted: 5 June 2018

(c) Springer Nature B.V. 2018

\begin{abstract}
Coir is a natural, lignin rich, fiber that can be found between the hard internal shell and the outer coat of a coconut. There are multiple products made from coir fibers but a significant amount of fibers accumulating from coconut processing remains unutilized. Coir fibers obtained from ripe (brown fibers) and unripe (white fibers) have a high lignin content about 41-42 wt $\%$, a low ash content $<15 \mathrm{wt} \%$ and a high heating value of about $18.5-19 \mathrm{MJ} \mathrm{kg}^{-1}$. The pelletizing properties were studied in a laboratory scale, single pellet press, and produced pellets were of high mechanical properties. Dynamic mechanical thermal analysis was used to identify the glass transition temperature of coir lignin and indicated that at the applied conditions the softening of coir lignin occurs at about $120-130{ }^{\circ} \mathrm{C}$, which is the usual temperature reached in an industrial scale pellet mill. These properties make coir a suitable raw material for fuel pellet production. Its high availability makes coir fibers a potential replacement for firewood and charcoal in developing countries, and thereby contributes to reduce deforestation.
\end{abstract}

Keywords Coir $\cdot$ Pellets $\cdot$ Biofuel $\cdot$ Lignin $\cdot$ Heating value $\cdot$ Glass transition temperature

\section{Statement of Novelty}

The novelty in this study is the comprehensive chemical, spectroscopic and thermo-mechanical characterization of coir fibers as a raw material for fuel pellet production.

Wolfgang Stelte

wost@dtu.dk; stelte@gmail.com

1 Center for Bachelor of Engineering Studies, Technical University of Denmark, Lautrupvang 15, 2750 Ballerup, Denmark

2 Biomass Science and Technology, Faculty of Science, University of Copenhagen, Rolighedsvej 23, 1958 Frederiksberg, Denmark

3 Forest Products Laboratory, United States Department of Agriculture, 1 Gifford Pinchot Dr., Madison, WI 53726-2398, USA

4 Embrapa Algodão, Empresa Brasileira de Pesquisa Agropecuária, Rua Oswaldo Cruz, 1143 - Centenario, Campina Grande, PB, Brazil

5 Embrapa Agroindústria Tropical, Empresa Brasileira de Pesquisa Agropecuária, Rua Dra. Sara Mesquita, 2270, Planalto do Pici, Fortaleza, CE, Brazil

\section{Introduction}

Coconuts are grown in more than 100 countries and autonomous regions of the world, resulting in an annual production of about 60.5 million tons for the year 2014 [1]. They represent a particularly important agribusiness in developing countries with tropical climate [2]. A variety of uses have been sought for the husks and shells, which remain after harvesting and processing of the coconuts. For example, some coconut-producing countries use coconut husks and shells as an alternative energy source, such as charcoal production [3].

Alternatively, coconut husks can be further processed into useful by-products such as coir. Coir is a natural fiber obtained from the husk of the coconut fruit (Cocos nucifera), a tropical plant of the Arecaceae (Palmae) family. In ripe coconuts, a husk, which consists of about $30-35 \%$ fibers, surrounds the hard seed and the remaining part is a particulate substance known as pith. Coir is a coarse, reddish and stiff fiber, rich in lignin and cellulose. During the 6-12 month growth period of a coconut the immature pale and soft coir fibers harden as layers of lignin are formed in their cell walls [2]. After the harvest, the fibrous layer of the husk is separated either manually or mechanically by crushing the husk. The pith remains as residue from the 
extraction process and can be used in horticulture or used to make renewable fertilizer [3] or used as a raw material for fuel pellet production [4].

Brown coir (made from ripe coconut) and white coir (made from unripe coconut) are available in large quantities in most tropical countries. The world production of coir fibre in 2014 was estimated by the Food and Agriculture Organization of the United Nations (FAO) [1] to be at about 1.13 million tons on global level. India is by far the country producing most coir and Indian production alone accounted for 544,000 tons. There is a well developed market for coir yarns and mats that amounts to, respectively, about 14,000 and 60,000 tons yearly [5]. Although there are multiple products made from coir fibers such as mats, brushes, mattresses and fishing nets, most of the fibers obtained from coconut processing remain unutilized for higher value uses [6]. Only at about $15 \%$ of the husk fibres are actually recovered for use [7, 8]. Much more efficient utilization is possible, especially using of shorter fibers, sometimes called fiber bits, that cannot be used for high value products such as rope or mat production.

The major drawback of coir fibers are their low bulk density which makes their handling expensive and difficult, limiting their market value. Evans et al. [9] have reported bulk densities of $40-80 \mathrm{~kg} \mathrm{~m}^{-3}$ for different sources of coir dust, and cut fibres can be expected to have even lower bulk densities. The bulk volume can be reduced significantly (factor 10-15) by grinding and pressing the fibers into high density pellets, which could potentially be used for domestic cooking and heating applications in developing countries or elsewhere, for example. Figure 1 illustrates the reduction in volume from cut fibers to powder and after pelletization.

Densification of fibers into pellets eases the handling, transportation and storage of fibrous biomass and is the most common method of reducing the logistic costs for solid biofuels and increase the energy density [10]. Pelletization results in a homogeneous, standardized product that can be handled at a lower cost and easily fed into a combustion system [11].
The use of fuel pellets made from agricultural residues such as coir could replace traditionally used firewood, and thus reduce uncontrolled deforestation which is a serious problem in many developing countries, resulting in land erosion and other environmental problems. Recent studies have shown that biomass pellets could be used in small pellet stoves, replacing traditional open fireplaces for cooking in developing countries, and as such significantly reduce indoor pollution and related health issues [12]. Pellet stoves are cheap to manufacture, and biomass pellets can be produced locally from local fiber residues, i.e. wood, agricultural grasses, husk and empty fruit bunches. Reed and Larsson have developed a low emission biomass gas stove for developing countries that can be used for cooking indoors [13]. The ash can be collected and used as fertilizer for local farming. Findings have shown that densification of the coirpith improves gasification processes [14]. Apart from heat and energy production, coir fiber pellets may also serve as raw materials for biorefinery and/or composite production processes [5].

However, not all biomass materials are suitable for commercial pellet production. Pelletization and the resulting pellet quality and processing costs depend on the chemical and physical properties of the raw material, which varies according to species, stage of maturity, climatic conditions and other factors. For example, a high lignin content will enhance the pellet quality, while high amounts of extractives (i.e. oils and waxes), can reduce the pellet's mechanical properties [15].

Coir fibers have good mechanical properties and are composed of at least one-third of lignin [16-20] making them a good candidate for pelletization. White coir has been reported to have a lignin content of about 37.2-43.9\% [18], whilst the brown coir lignin content may range from 38.3 to $45.8 \%$ [19, 20]. A previous study based on extracted coir lignin indicates that lignin extracted from coir fibers undergoes a glass transition at about $140{ }^{\circ} \mathrm{C}$, with some temperature variation based on degree of maturity and moisture content [16]. It was claimed that coir fibers dehydrate and crosslink upon heating, resulting in an irreversible hardening
Fig. 1 Volume decrease of $4 \mathrm{~g}$ coir fibers by milling and pelletization

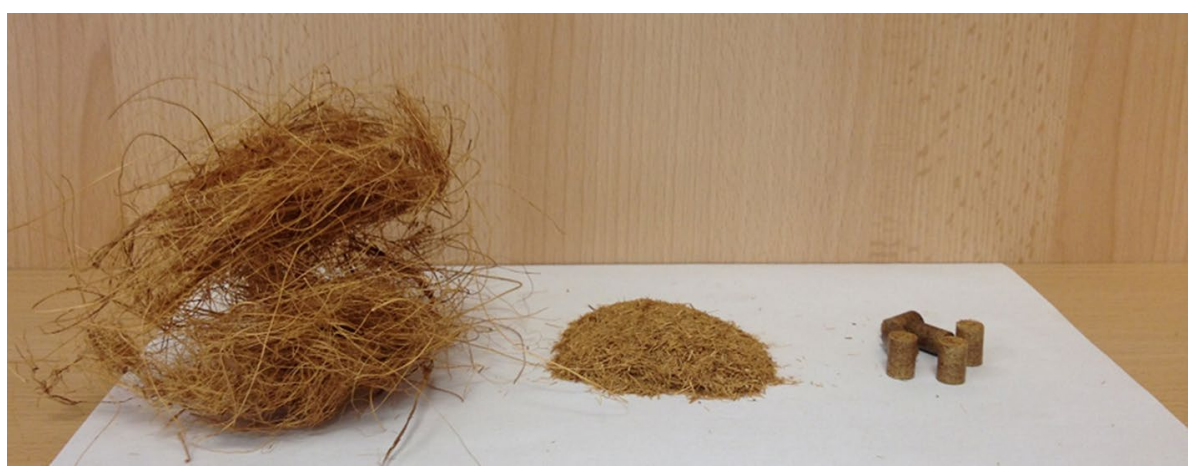


of the fiber after cooling. Coir fibers were therefore suggested as an ideal raw material high-density fiberboard production [16], a process that in many ways resembles pelletization with respect to temperature and pressure.

The present study investigates the potential of coir fibers for fuel pellet production processes. The heating value (HHV) of the pellets was determined using a bomb calorimeter and the fibers were analyzed for their composition by means of acid hydrolysis and subsequent sugar analysis using high-performance liquid chromatography (HPLC). The fiber surface was characterized using infrared spectroscopy and the thermomechanical properties were determined using dynamic mechanical thermal analysis (DMTA). The latter gives information on the flow characteristics of the lignin in the fibers, and can be useful for optimizing commercial pelletizing operations. The pelletizing properties of coir were tested using a single pellet press tool that allows an exact adjustment and optimization of the pelletizing conditions. Similar tests using other biomass materials have shown the value of this method and its correlation to production scale pellet mills [21, 22]. The mechanical strength of the produced pellets was determined by means of compression testing.

\section{Materials and Methods}

\section{Materials}

Coconuts (Cocos nucifera) were harvested in August 2011, at Paraipaba, Ceará State, Brazil under tropical monsoon climate conditions, Köppen climate class Aw [23]. The ripe and unripe nuts were processed in a coconut processing facility at Paraipaba. Initially, the unripe husks were ground in a shredder machine with blades and hammers and pressed in a horizontal roller press machine. Finally, the material was sorted into pith and coir. The ripe husks were processed in the same way, without the press step. The fibers were dried to prevent microbiological degradation and to enable storage of the material until its utilization. Drying was made in an air blown oven at $105{ }^{\circ} \mathrm{C}$ for $15 \mathrm{~min}$. The dried fibers were stored in an airtight container, in a dry and dark place until utilization. The fibers used for pelletizing trials were ground to a particle size $<2 \mathrm{~mm}$ using a knife mill (Cutting Mill SM 300 , Retsch, Germany) and stored in a climate chamber with $65 \%$ relative humidity $(\mathrm{RH})$ at $20^{\circ} \mathrm{C}$ until an equilibrium moisture content was reached.

\section{Fiber Analysis}

The composition of the dry samples milled to $<1 \mathrm{~mm}$ particle size was analyzed using a two-step strong acid hydrolysis method developed by Sluiter et al. [24]. The detailed procedure used in this study has previously been described by Kristensen et al. [25] The moisture content was determined using a moisture analyzer (MA 30, Sartorius, Germany). Monosaccharides (D-glucose, D-xylose and L-arabinose) were quantified according to Kristensen et al. using HPLC (Summit system, Dionex, USA) equipped with an RI-detector (Shimadzu, Japan). The separation was performed in a Phenomenex Rezex RHM column at $80^{\circ} \mathrm{C}$ with $5 \mathrm{mM} \mathrm{H}_{2} \mathrm{SO}_{4}$ as an eluent at a flow rate of $0.6 \mathrm{ml} \mathrm{min}{ }^{-1}$ [25]. Klason lignin content was determined based on the filter cake, subtracting the ash content after incinerating the residues from the strong acid hydrolysis at $550{ }^{\circ} \mathrm{C}$ for $3 \mathrm{~h}$. The amount of ash was determined according to ASTM E175501(2007), which is a standard test method for ash in biomass.

\section{Infrared Spectroscopy}

Attenuated Total Reflectance (ATR) FTIR spectroscopy was used to study the surface of the biomass particles. Spectra were recorded at $30{ }^{\circ} \mathrm{C}$ using a Nicolet 6700 FT-IR spectrometer (Thermo Electron Corporation, USA), equipped with a temperature-adjustable ATR accessory (Smart Golden Gate diamond ATR accessory, Thermo Electron Corporation, USA). Samples were dried at $105^{\circ} \mathrm{C}$ for $4 \mathrm{~h}$ and stored in airtight containers until analysis. All spectra are obtained as the average of six independent sample spectra. The spectra are all baseline corrected and ATR-corrected (for dispersion), then normalized such that the strongest band around $900-1100 \mathrm{~cm}^{-1}$ gave an absorbance value of 1 .

To ensure good contact, all samples were pressed against the diamond surface using a metal rod with consistent pressure. All spectra were obtained with 200 scans for the background (no sample) and 100 scans for the sample with a resolution of $4 \mathrm{~cm}^{-1}$.

\section{Single Pellet Press Test}

White and brown coir was pelletized using a single pellet press as described in earlier studies [26, 27]. The single pellet unit consisted of a cylindrical die, $8 \mathrm{~mm}$ in diameter and made of hardened steel, lagged with heating elements and thermal insulation. The temperature of the die wall was controlled using a thermocouple connected to a control unit. The temperature was set to two different temperatures, above $\left(130{ }^{\circ} \mathrm{C}\right)$ and below $\left(60^{\circ} \mathrm{C}\right)$ the glass transition temperature of lignin. The end of the die was closed using a removable backstop. Force was applied to the pellet unit using a universal testing system (AGX, Shimadzu, Japan) and detected using a $200 \mathrm{kN}$ load cell. Data recorded was the compression force and the friction (force that is required to extrude the pellet from the press channel). For testing $750 \mathrm{mg}$ of sample material with particle size of $1-2 \mathrm{~mm}$ was compressed at a 
rate of $100 \mathrm{~mm} \mathrm{~min}^{-1}$ until a maximum pressure of $300 \mathrm{MPa}$ was reached and hold for $5 \mathrm{~s}$. The chosen maximum pressure can be regarded to be in the range of pressures typically obtained in commercial pelletizing processes [28, 29]. Subsequent to compression, the bottom piston was removed from the die and the pellet was pressed out of the channel at a rate of $100 \mathrm{~mm} \mathrm{~min}^{-1}$. The static friction is the force required to set the pellet into motion when extruding the pellet from the die. The average value of at least five measurements was determined and a $95 \%$ confidence interval calculated. It has been shown earlier that the determined friction values can be correlated to the energy consumption of an industrial scale pellet press [22].

\section{Pellet Characterization}

The pellets produced from the single pellet press were cylindrical with $8 \mathrm{~mm}$ in diameter and about $12 \mathrm{~mm}$ in length. The pellets were left to cool overnight, and the pellet strength was determined by crushing the pellet perpendicular to the length of the pellet as described earlier [21, 27]. Prior to this, the length, diameter, and mass were measured for density calculation. 4-10 replicates were made for each sample. The average value was determined and a $95 \%$ confidence interval calculated.

\section{Heating Value}

A bomb calorimeter (6300, Parr Instrument Company, USA) was used to determine the higher HHV ( $\mathrm{MJ} \mathrm{kg}^{-1}$ ) of coir fibers according to European standard EN 14918. Ground material with a particle size $<1 \mathrm{~mm}$ was placed in a metal crucible and fired inside the bomb calorimeter using an ignition wire in the presence of oxygen. The measurements were repeated three times and reported as an average value.

\section{Dynamic Mechanical Thermal Analysis (DMTA)}

The glass transition temperatures of coir amorphous polymers were determined by means of DMTA (Q800, TAInstruments, USA) using a single cantilever grip as described in one of our earlier studies [30]. Specimens were prepared by pressing the conditioned coir fibers into fiber mats using a laboratory hot press at $130{ }^{\circ} \mathrm{C}$ applying a pressure of about $50 \mathrm{MPa}$ for $1 \mathrm{~min}$. The resulting fiber mats were cut into rectangular specimens and one-half of them were dried at $105^{\circ} \mathrm{C}$ over night and kept dry in a desiccator. The other half was conditioned at $65 \mathrm{RH}$ and $27^{\circ} \mathrm{C}$ for 3 weeks. The resulting moisture content of the specimen based on dry weight was determined to be $11.8 \mathrm{wt}( \pm 0.9 \mathrm{wt} \%)$ for the white coir and $10.1 \mathrm{wt} \%( \pm 0.8 \mathrm{wt} \%)$ for the white coir. Measurements were conducted between -60 and $200{ }^{\circ} \mathrm{C}$ with an amplitude of $15 \mu \mathrm{m}$ at a frequency of $1 \mathrm{~Hz}$. The loss factor $(\tan \delta)$ were determined and used for obtaining information on the thermo-mechanical behavior of the amorphous polymers (lignin and hemicellulose) to explain the flow behavior and, indirectly, the strength of the pellets. Measurements were repeated twice to verify the results.

\section{Results and Discussion}

\section{Fiber Analysis}

Standard fiber analysis of white and brown coir as shown in Table 1 indicate a high lignin content of about $42.2 \mathrm{wt} \%$ for brown and $40.8 \mathrm{wt} \%$ for white coir fibers based on dry basis. In an earlier study the lignin content of different wood species has been determined using exactly the same analysis protocol to be at about $25.0-35.0 \mathrm{wt} \%$ and which is significantly lower to what has been determined for coir fibers [19]. The ash content is 1.75 (brown coir)-2.46 wt\% (white coir) and this is still in the range of what typical firewood can contain. Both the high lignin content and the relatively low ash content suggest that coir may serve as an excellent feedstock for fuel pellet production.

\section{Infrared Spectroscopy}

The chemical composition of the fiber surface has been studied by means of ATR-FTIR. The bands at 2925 and $2850 \mathrm{~cm}^{-1}$ are associated with $\mathrm{CH}$ stretching vibrations of lipids that can be linked to surface waxes of the plant cuticle [31]. Those waxes have earlier been shown to have a potentially negative effect on the pelletizing properties of biomass, especially when present in high concentration [21]. However the signal intensity is rather weak compared to analysis data published in an earlier study on wheat straw, using the same equipment and analysis method, which was shown to have high wax content and poor densification properties [21]. This indicates that coir has only a low wax content that will most likely not have a negative effect on the pelletizing process. Literature data indicates that coir fibers have a lipid content of about $1-5 \mathrm{wt} \%$ [16].

The bands at 1515 and $1600 \mathrm{~cm}^{-1}$ are associated to with the aromatic ring structures of lignin [32-34]. There are some differences between the white and the brown coir. The larger lignin bands for brown coir indicates that the ripening

Table 1 Chemical composition of white and brown coir fibers

\begin{tabular}{lllll}
\hline & $\begin{array}{l}\text { Hemicellu- } \\
\text { oses wt\% }\end{array}$ & Celluose wt\% & Lignin wt\% & Ash wt\% \\
\hline White coir & 17.6 & 26.7 & 40.8 & 2.5 \\
Brown coir & 16.9 & 28.5 & 42.2 & 1.8 \\
\hline
\end{tabular}


process enhances the lignin content. This observation is supported by the chemical analysis (Table 1). Furthermore, the decrease in the band at $1725 \mathrm{~cm}^{-1}$, associated with the carbonyl groups of the hemicelluloses [32-34], suggests that the hemicellulose content might decrease during the ripening due to degradation or by out-washing (Fig. 2).

\section{Pelletizing Tests}

Both frictions (Fig. 3) and compression strength (Fig. 4) of the pellets are affected by the temperature of the pellet die. At $130{ }^{\circ} \mathrm{C}$ the friction generated in the press channel of a pellet press is low, for both for white and brown coir. Lowering the die temperature to $60^{\circ} \mathrm{C}$ the friction is considerably higher, especially for the brown coir. The pellet strength which is a measure for the pellet quality is shown in Fig. 4 and pellets pressed at $130{ }^{\circ} \mathrm{C}$ are considerably stronger than pellets pressed at $60{ }^{\circ} \mathrm{C}$. This is most likely because the higher temperature increases the flow of lignin resulting in

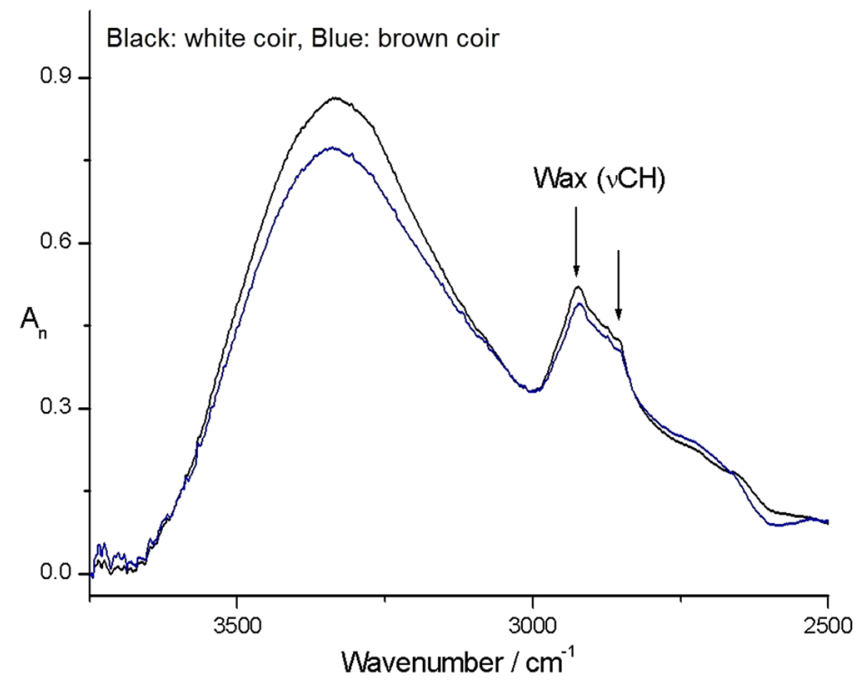

better inter-fiber bonding. Comparing the measured strength data with strength data of convetional wood pellets that have been tested in an earlier study using the same experimental set up, indicates that the mechanical properties of coir pellets are similar or superior to pellets made from wood or wheat straw [26, 35].

Figure 5 shows that the unit density of coir pellets pressed at $130{ }^{\circ} \mathrm{C}$ is higher compared to pellets pressed at $60{ }^{\circ} \mathrm{C}$. Better bonding results in higher unit density of the pellets, since they expand less compared to pellets with poor interparticle bonding. This phenomenon is commonly reported as the spring back effect in the pellet literature.

\section{Heating Value}

The higher HHV for white coir is HHV $=18.5 \pm 0.3 \mathrm{MJ} /$ $\mathrm{kg}$ and for brown coir HHV $=19.0 \pm 0.2 \mathrm{MJ} / \mathrm{kg}$. The results indicate a slight increase of HHV during the maturation process of the coconut. This could be due to a partial

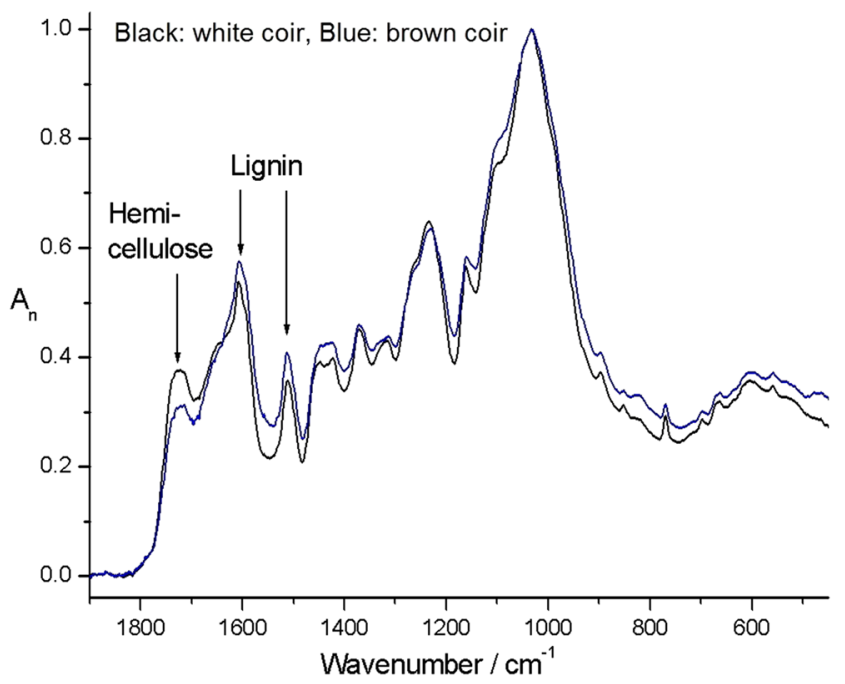

Fig. 2 Averaged ATR-FTIR spectra of white (black) and brown coir (blue). Left: Bands at 2925 and $2850 \mathrm{~cm}^{-1}$ associated to CH stretching of surface waxes. Right: The bands at 1515 and $1600 \mathrm{~cm}^{-1}$ assigned to lignin and at $1725 \mathrm{~cm}^{-1}$ assigned to hemicellulose. (Color figure online)

Fig. 3 Friction generated in the press channel of a pellet press when extruding a pellet pressed of white and brown coir at 60 and $130{ }^{\circ} \mathrm{C}$ die temperature. Error bars indicate a $95 \%$ confidence interval

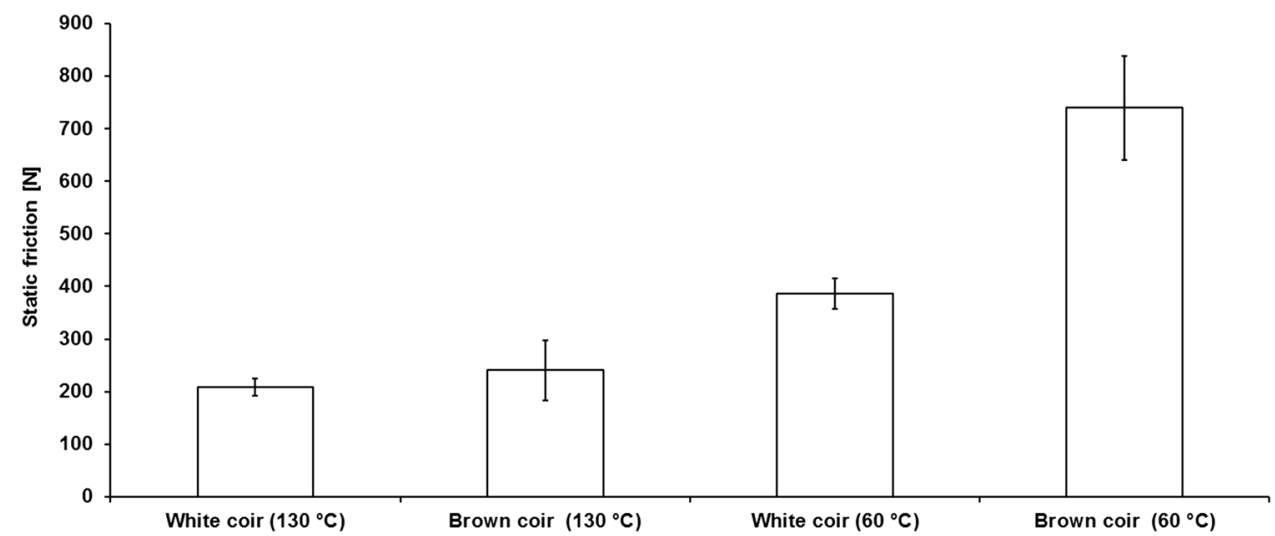


Fig. 4 Compression strength of pellets made from white and brown coir at 60 and $130{ }^{\circ} \mathrm{C}$. Error bars indicate a 95\% confidence interval

Fig. 5 Pellet unit density. Error bars indicate $95 \%$ confidence interval
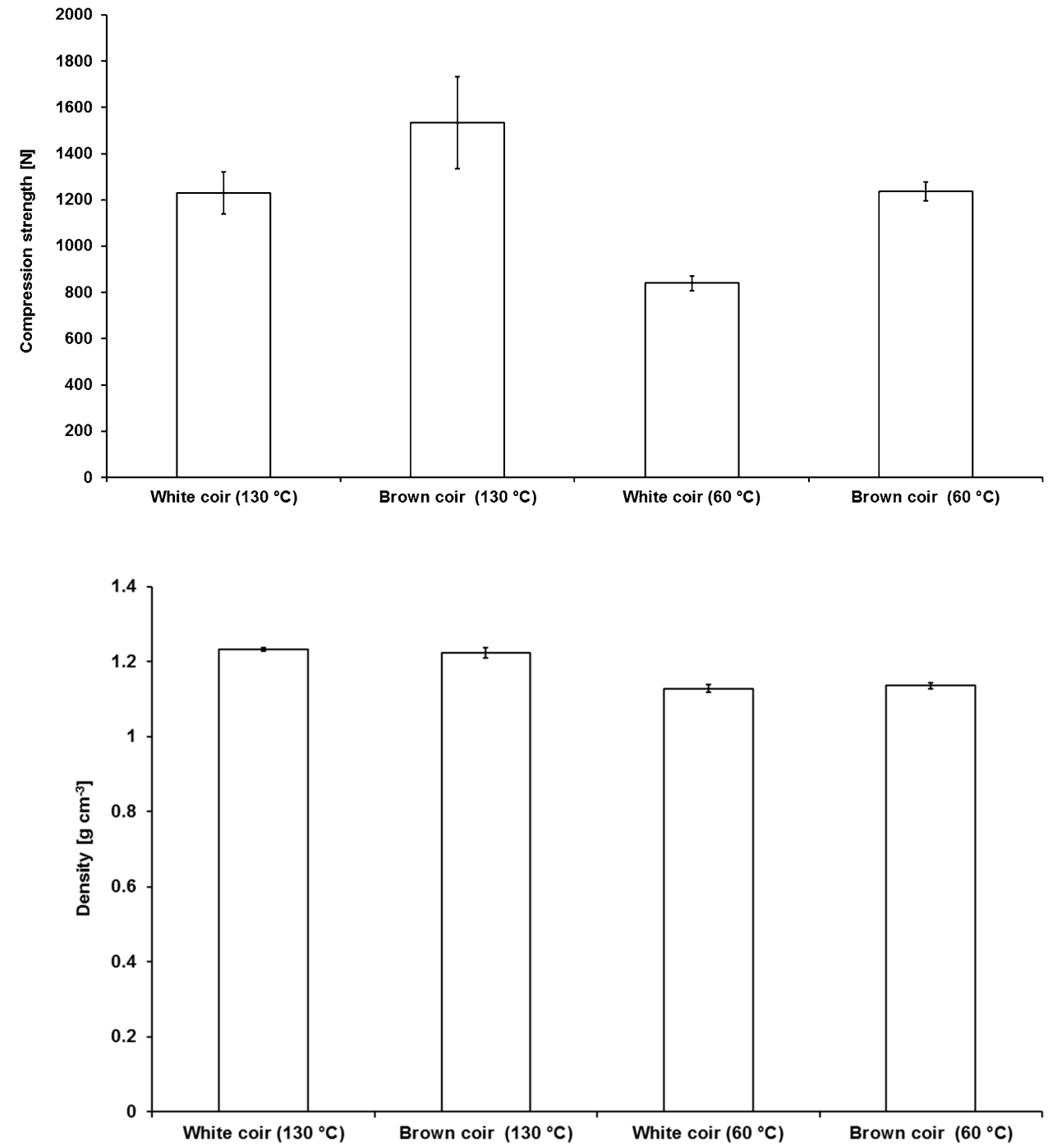

degradation of hemicelluloses during the ripening process caused by hemicellulose degrading enzymes and a higher lignin content, which has been observed in other species [36, 37].

Compared to other biomass resources, the HHV for coir is similar to those of other plant husk and shell materials (i.e. hazelnut shell, olive husks) [38] and close to what has been determined for hard and softwood materials, which is the main raw material for fuel pellet production today.

The HHV of biomass can be directly correlated to its lignin content [39]. The lignin content of coir is relatively high compared to many other types of agricultural residues and wood, making coir an interesting feedstock for fuel pellet production.

\section{Dynamic Mechanical Thermal Analysis (DMTA)}

In commercial palletization processes the biomass is compressed at high pressure between 210 and $450 \mathrm{MPa}$ [28] and high temperature which softens the lignin and hemicelluloses in the fibers. The high pressure results in a collapse of the cell vacuole and ruptures the cell walls, releasing lignin and hemicellulose. In an ideal case, the lignin starts to flow and forms an inter-particle network of molten polymer held together by non-covalent interactions such as hydrogen bonding [21]. The network will solidify upon cooling and form a composite like structure of individual fibers and particles. The softening temperature of a polymer is usually referred to as the glass transition temperature $\left(\mathrm{T}_{\mathrm{g}}\right)$ and defines the temperature where the polymer chains become able to move and rotate freely, allowing the polymer to flow and interact with neighboring polymer chains. Water is a crucial component since it acts as plasticizer, interacting with the lignin by hydrogen bonding and reducing the $\mathrm{T}_{\mathrm{g}}$ most likely by reducing steric hindrance of the polymer chain movement. This is expected to result in a better flow and penetration of the lignin in between the biomass particles, enhancing the bonding strength and thus the 
mechanical properties of the pellet [40-42]. Therefore, the $T_{g}$ of the coir fibers and the influence of moisture on it were investigated using DMTA.

The loss factor $(\tan \delta)$ for both dry fibers and fibers conditioned at $27{ }^{\circ} \mathrm{C}$ and $65 \%$ relative humidity (RH) are shown in Fig. 6. At $65 \% \mathrm{RH}$, the brown and white fibers had moisture contents of $11.8 \pm 0.9$ and $10.1 \pm 0.8 \%$, respectively. There is a major transition $\left(\alpha_{2}\right.$ peak) at about $120{ }^{\circ} \mathrm{C}$ for brown coir and at about $130{ }^{\circ} \mathrm{C}$ for white coir which is most likely the lignin glass transition [30]. The transition is broad and starts at a lower temperature which is most likely due to the heterogeneous nature of lignin. There is a minor $\alpha_{1}$ transition of the moist fibers at about $10{ }^{\circ} \mathrm{C}$ (brown coir) and $20{ }^{\circ} \mathrm{C}$ (white coir) which could be attributed to a glass transition for hemicelluloses [30]. However this needs further studies for confirmation.

The dry fibers behave differently. There is a small transition at about $145^{\circ} \mathrm{C}$ for both brown and white coir. Its origin cannot be identified exactly but it has been suggested that, for wood materials, it might be a secondary transition of lignin $[43,44]$. The transitions for the dry fibers are significantly higher by about $20^{\circ} \mathrm{C}$, suggesting that higher temperatures and pressures will be needed to produce strong pellets.

For both brown and white coir fibers, the temperatures of the $\tan \delta$ peak (arrows in Fig. 6) are reduced with moisture content, indicating that flow occurs at lower temperatures for the moist fibers. Nevertheless the transition temperature is still above the pelletizing temperature of $60^{\circ} \mathrm{C}$ used in some of the single pellet tests.

At $130{ }^{\circ} \mathrm{C}$ pelletizing temperature it can be expected that lignin is flowing, resulting in more interpenetration of lignin between fibers during pelletization. This is also reflected in increased pellet strength. Ripe (i.e. brown) fibers seem to have a slightly lower transition temperature than the unripe

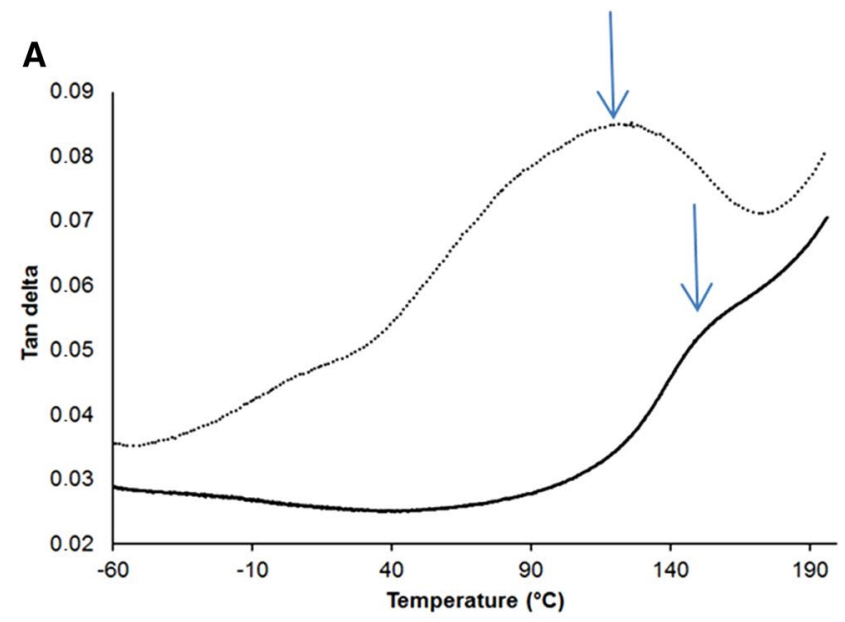

(i.e. white) fibers, which might be due to compositional differences, explaining the slightly higher strengths of the pellets made from them. The positions of observed transitions of the moist fibers are in the range or below temperatures reached in the press channels of a commercial pellet mill. These results are in accord with earlier results showing that pellet stability peaks within a relatively small window of moisture content between 5 and 20\% depending on biomass type [45].

\section{Conclusions}

The present study has shown that coir fibers are a suitable raw material for fuel pellet production, with fairly high energy content and sufficient strength as compared to presently used biomass pellets. Both ripe (brown) and unripe (white) coir are suitable raw materials for pelletizing processes. The strength and HHV of fuel pellets produced from brown coir fibers is slightly higher compared to fuel pellets produced from white coir. Furthermore the softening of the lignin in brown coir fibers occurs at slightly lower temperatures and the ash content of brown coir fibers is lower then in white coir. These differences make brown coir the preferred choice of raw material for fuel pellet production. The processing temperature has an important effect on the friction and thus the energy consumption of the pelletizing process. A processing temperature above the lignin glass transition temperature is advisable, and steam-pretreatment of the biomass prior pelletization may be considered as suitable conditioning step to increase the temperature and the moisture content in the raw material. This will likely lower the pellet mills energy consumption, reduce friction related wear of the mechanical parts and increase the product quality at the

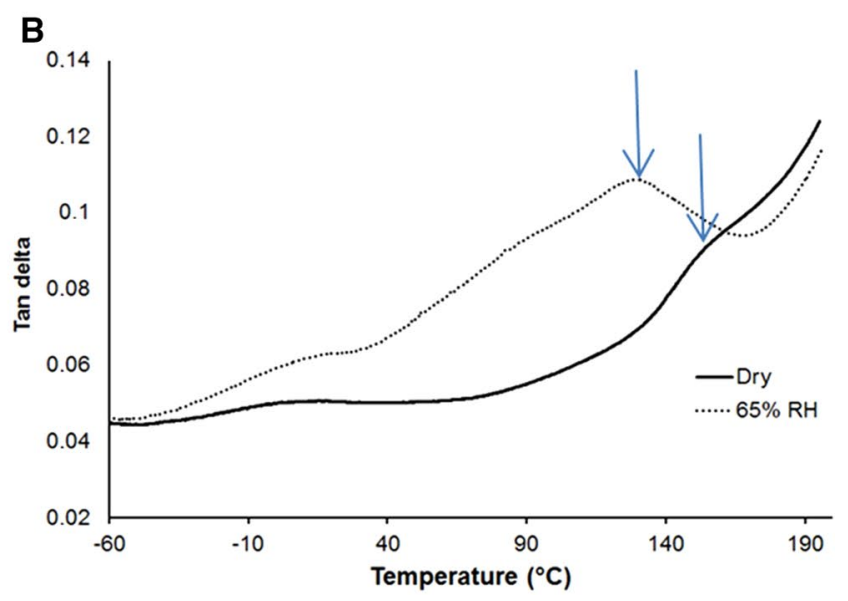

Fig. 6 The loss factor $(\tan \delta)$ of coir amorphous polymers at different moisture contents. Transition peaks are indicated by arrows. The graphs compare $\mathbf{a}$ brown coir and $\mathbf{b}$ white coir 
same time. The next steps will be to test pelletizing properties of coir fibers in a continuous pellet mill and further process optimization and an economic analysis. Also the use of fiber bits (short fibers that cannot be used for high value products) and coir pith as raw materials have to be evaluated. The thermo-mechanical properties of coir and the high stability of coir pellets indicate that this type of fiber might also be a suitable raw material for other high value applications i.e. for boards without external adhesives.

\section{References}

1. Food and Agriculture Organization of the United Nations, FAOSTAT database. http://faostat.fao.org. Accessed 20 Sept 2017

2. Harish, D., Michael, P., Bensely, A., Mohan Lal, D., Rajadurai, A.: Mechanical property evaluation of natural fiber coir composite. Mater. Charact. 60(1), 44-49 (2009)

3. Van Dam, J.E.G.: Coir processing technologies, improvement of drying, softening bleaching and dyeing coir fibre/yarn and printing coir floor coverings. Technical paper No. 6. Food and Agricultural Organization of the United Nations, New York (2002)

4. Shree, M.A., Iyappan, K., Srinivasakannan, C.: Preparation and characterization of bio fuel from industrial waste. J. Sustain. Dev. 2(1), 71-74 (2009)

5. Moir, B.: Coir globally: status and perspectives. In: Proceeding of International Coir Convention, Colombo, Sri Lanka (2002)

6. Eldho, A., Deepa, B., Pothen, L.A., Cintil, J., Thomas, S., John, M.J., Anandjiwala, R., Narine, S.S.: Environmental friendly method for the extraction of coir fibre and isolation of nanofibre. Carbohydr. Polym. 92(2), 1477-1483 (2012)

7. Gu, H.: Tensile behaviours of the coir fibre and related composites after $\mathrm{NaOH}$ treatment. Mater. Des. 30(9), 3931-3934 (2009)

8. Wang, W., Gu, H.: Characterisation and utilization of natural coconut fibres composites. Mater. Des. 30(7), 2741-2744 (2009)

9. Evans, M.R., Konduru, S., Stamps, R.H.: Source variation in physical and chemical properties of coconut coir dust. HortScience 31(6), 965-967 (1996)

10. Stelte, W., Sanadi, A.R., Shang, L., Holm, J.K., Ahrenfeldt, J., Henriksen, U.B.: Recent developments in biomass pelletizationa review. Bioresources 7(3), 4451-4490 (2013)

11. Obernberger, I., Thek, G.: The Pellet Handbook: the Production and Thermal Utilisation of Pellets. Earthscan, Routledge (2010)

12. Kumari, S., Singal, S.: Use of clean green fuel energy from biomass in rural households of Haryana (India). In: 20th European Biomass Conference and Exhibition, Milan, Italy, 18-22 June 2012

13. Reed, T.B., Larson, R.: A wood-gas stove for developing countries. Energ. Sustain. Dev. 3, 34-37 (1996)

14. Ramadhas, A.S., Jayaraj, S., Muraleedharan, C.: Power generation using coir-pith and wood derived producer gas in diesel engines. Fuel Process. Technol. 87(10), 849-853 (2006)

15. Stelte, W., Holm, J.K., Sanadi, A.R., Barsberg, S., Ahrenfeldt, J., Henriksen, U.B.: A study of bonding and failure mechanisms in fuel pellets from different biomass resources. Biomass Bioenerg. 35(2), 910-918 (2011)

16. van Dam, J.E.G., van den Oever, M.J.A., Keijsers, E.R.P., van der Putten, J.V., Anayron, C., Josol, F., Peralta, A.: Process for production of high density/high performance binderless boards from whole coconut husk: part 2: coconut husk morphology, composition and properties. Ind. Crop Prod. 24(2), 96-104 (2006)
17. van Dam, J.E.G., van den Oever, M.J.A., Teunissen, W., Keijsers, E.R.P., Peralta, A.G.: Process for production of high density/high performance binderless boards from whole coconut husk: part 1: lignin as intrinsic thermosetting binder resin. Ind. Crop Prod. 19(3), 207-216 (2006)

18. Corradini, E., de Freitas Rosa, M., de Macedo, B.P., Paladin, P.D., Mattoso, L.H.C.: Chemical composition, thermal and mechanical properties for cultivars of immature coconut fibers. Rev. Bras. Frutic. 31(3), 837-846 (2009)

19. Satyanarayana, K.G., Guimarães, J.L., Wypych, F.: Studies on lignocellulosic fibers of Brazil. Part I: source, production, morphology, properties and applications. Composites A 38(7), 1694-1709 (2007)

20. Silva, G.G., De Souza, D.A., Machado, J.C., Hourston, D.J.: Mechanical and thermal characterization of native Brazilian coir fiber. J. Appl. Polym. Sci. 76(7), 1197-1206 (2000)

21. Stelte, W., Holm, J.K., Sanadi, A.R., Barsberg, S., Ahrenfeldt, J., Henriksen, U.B.A.: Study of bonding and failure mechanism in fuel pellets produced from different biomass resources. Biomass Bioenerg. 35(2), 910-918 (2011)

22. Stelte, W., Dahl, J., Nielsen, N.P.K., Hansen, H.O.: Densification concepts for torrefied biomass. In: 20th European Biomass Conference and Exhibition, Milan, Italy, 18-22 June 2012

23. Aguira, M.J.N., de Lima, J.B., Barreto, J.H.C., Carneiro, F.A., Badu, F.O.: Dados climatológicos: Estação de Paraipaba 2001. Embrapa Agroindústria 59, 25 (2002)

24. Sluiter, A., Hames, B., Ruiz, R., Scarlata, C., Sluiter, J., Templeton, D., Crocker, D.: Determination of structural carbohydrates and lignin in biomass. Technical Report NREL/TP-510-42618, Version 07-08-2011, National Renewable Energy Laboratory, Golden, Colorado (2004)

25. Kristensen, J.B., Thygesen, L.G., Felby, C., Jorgensen, H., Elder, T.: Cell-wall structural changes in wheat straw pretreated for bioethanol production. Biotechnol. Biofuels 1(1), 1-9 (2000)

26. Stelte, W., Nielsen, N.P.K., Hansen, H.O., Dahl, J., Shang, L., Sanadi, A.R.: Reprint of: Pelletizing properties of torrefied wheat straw. Biomass Bioenerg. 53, 105-112 (2013)

27. Rudolfsson, M., Stelte, W., Lestander, T.A.: Process optimization of combined biomass torrefaction and pelletization for fuel pellet production-A parametric study. Appl. Energ. 140, 378-384 (2015)

28. Leaver, R.H.: Wood pellet fuel and the residential market. In: Proceedings of the Ninth Biennial Bioenergy Conference, Bioenergy (2000)

29. Nielsen, N.P.K., Gardner, D.J., Poulsen, T., Felby, C.: Importance of temperature, moisture content, and species for the conversion process of wood residues into fuel pellets. Wood Fiber Sci. 41(4), 414-425 (2009)

30. Stelte, W., Clemons, C., Holm, J.K., Ahrenfeldt, J., Henriksen, U.B., Sanadi, A.R.: Thermal transitions of the amorphous polymers in wheat straw. Ind. Crop Prod. 34(1), 1053-1056 (2011)

31. Merk, S., Blume, A., Riederer, M.: Phase behaviour and crystallinity of plant cuticular waxes studied by Fourier transform infrared spectroscopy. Planta 204(1), 44-53 (1997)

32. Pandey, K.K.: A study of chemical structure of soft and hardwood and wood polymers by FTIR spectroscopy. J. Appl. Polym. Sci. 71(12), 1969-1975 (1999)

33. Faix, O.: Classification of lignins from different botanical origins by FT-IR spectroscopy. Holzforschung 45(1), 21-28 (1991)

34. Stewart, D.H., Wilson, M., Hendra, P.J., Morrison, I.M.: Fouriertransform infrared and Raman spectroscopic study of biochemical and chemical treatments of oak wood (Quercus rubra) and barley (Hordeum vulgare) straw. J. Agric. Food Chem. 43(8), 2219-2225 (1995)

35. Shang, L., Nielsen, N.P.K., Stelte, W., Dahl, J., Ahrenfeldt, J., Holm, J.K., Arnavat, M.P., Bach, L.S., Henriksen, U.B.: Lab and 
bench scale pelletization of torrefied wood chips-process optimization and pellet quality. Bioenerg. Res. 7(1), 87-94 (2014)

36. Yamaki, S., Kakiuchi, N.: Changes in hemicellulose-degrading enzymes during development and ripening of Japanese pear fruit. Plant Cell Physiol. 20(2), 301-309 (1979)

37. McCollum, T.G., Huber, D.J., Cantliffe, D.J.: Modification of polyuronides and hemicelluloses during muskmelon fruit softening. Physiol. Plant. 76(3), 303-308 (1989)

38. Demirbaş, A.: Calculation of higher heating values of biomass fuels. Fuel 76(5), 431-434 (1997)

39. Demirbaş, A.: Relationships between lignin contents and heating values of biomass. Energy Convers. Manag. 42(2), 183-188 (2001)

40. Olsson, A.M., Salmen, L.: The effect of lignin composition on the viscoelastic properties of wood. Nord. Pulp Pap. Res. J. 12(3), 140-144 (1997)
41. Salmen, L., Olsson, A.M.: Interaction between hemicellulose, lignin and cellulose: structure-property relationships. J Pulp Pap. Sci. 24(3), 99-103 (1998)

42. Salmen, L.: Viscoelastic properties of in situ lignin under watersaturated conditions. J. Mater. Sci. 19(9), 3090-3096 (1984)

43. Sugiyama, M., Obataya, E., Norimoto, M.: Viscoelastic properties of the matrix substance of chemically treated wood. J. Mater. Sci. 33(14), 3505-3510 (1998)

44. Sun, N., Das, S., Frazier, C.E.: Dynamic mechanical analysis of dry wood: linear viscoelastic response region and effects of minor moisture changes. Holzforschung 61(1), 28-33 (2007)

45. Stelte, W., Holm, J.K., Sanadi, A.R., Barsberg, S., Ahrenfeldt, J., Henriksen, U.B.: Fuel pellets from biomass: the importance of the pelletizing pressure and its dependency on the processing conditions. Fuel 90(11), 3285-3290 (2011) 